\title{
Geoprocessamento aplicado à identificação de áreas aptas para a implantação de unidades de conservação no Vale do Taquari, RS
}

\author{
Geoprocessing applied to the identification of further areas for the \\ implantation of conservation units in the Vale do Taquari, RS
}

\author{
Cleberton Diego Bianchini ${ }^{1}$ \\ Guilherme Garcia de Oliveira ${ }^{2}$
}

Recebido em agosto de 2018.

Aprovado em janeiro de 2019.

\begin{abstract}
RESUMO
Estudos e abordagens integradas para o planejamento ambiental e a redução dos impactos na natureza são fundamentais em função da complexidade do meio ambiente, da intervenção antrópica pouco organizada e da crescente utilização de recursos naturais. O uso de geotecnologias facilita e agiliza o trabalho de diagnóstico ambiental para definir áreas mais apropriadas para a conservação. Este estudo tem como objetivo determinar as áreas mais indicadas para a implantação de unidades de conservação (UCs) no Vale do Taquari, RS, Brasil, utilizando ferramentas de geoprocessamento. Utilizando-se a base de remanescentes da Mata Atlântica, extraiu-se os fragmentos vegetais com área igual ou maior que 100 ha. Com base nesses fragmentos foi realizada a definição das variáveis de entrada, o reescalonamento e a determinação dos pesos de cada variável, utilizando-se uma técnica de escolha baseada na lógica da comparação pareada denominada AHP (Processo Analítico Hierárquico). O resultado foi um mapa de ordenamento contendo os fragmentos com maior aptidão para implantação de UCs. No total, foram extraídos 235 fragmentos de vegetação e as variáveis analisadas em cada fragmento com seus respectivos pesos foram: o tamanho dos fragmentos $(0,28)$, densidade de florestas $(0,23)$, declividade média $(0,08)$, índice de forma $(0,16)$, distância média das rodovias $(0,06)$ e das áreas urbanas $(0,05)$, e densidade de nascentes $(0,14)$. A multiplicação dos pesos com suas respectivas variáveis reescalonadas resultou em um mapa com aptidão de 0 a 100. A área que apresentou a maior aptidão foi o fragmento conhecido regionalmente como Morro Gaúcho. Podese concluir que a metodologia adotada ofereceu resultados consistentes, podendo ser utilizada para pré-selecionar futuras áreas de conservação.
\end{abstract}

${ }^{1}$ Organização Não Governamental Ecobé, Brasil. E-mail: cleberton-db@hotmail.com

${ }^{2}$ Universidade Federal do Rio Grande do Sul. Departamento Interdisciplinar. Programa de Pósgraduação em Sensoriamento Remoto, Brasil. E-mail: g.g.oliveira10@gmail.com 
PALAVRAS-CHAVE: Geotecnologias. Análise multicritério. Meio ambiente. Preservação da natureza.

\begin{abstract}
Integrated studies and approaches to environmental planning and the reduction of impacts on nature are fundamental due to the complexity of the environment, the anthropogenic intervention poorly organized and the increasing use of natural resources. The use of geotechnologies assists in the environmental diagnosis to define areas more appropriate for the conservation. The aims of this study is to determine the most suitable areas for the implementation of conservation units in Vale do Taquari, RS, Brazil, using geoprocessing tools. We selected the vegetal fragments with an area greater than or equal to 100 ha using the digital map of remnants of the Atlantic Forest. Based on these fragments, we defined the input variables, the rescaling and the determination of the weights of each variable using the Analytical Hierarchy Process method (AHP). Then, we performed a map algebra, multiplying the weights with their respective variables and the result was an ordering containing the fragments with greater aptitude for implantation of conservation units. We selected 235 fragments of vegetation. The variables analyzed in each fragment with their respective weights were: fragment size (0.28), forest density (0.23), mean slope (0.08), shape index (0.16), mean distance of highways (0.06) and urban areas (0.05), and upstream density (0.14). The multiplication of the weights with their respective rescaled variables resulted in a map with aptitude from 0 to 100 . The fragment that presented the greatest aptitude was the fragment known regionally as Morro Gaúcho. We conclude that the methodology adopted offers consistent results, and can be used to pre-select future conservation areas.
\end{abstract}

KEYWORDS: Geotechnologies. Multi-criteria analysis. Environment. Nature preservation.

$$
* * *
$$

\title{
Introdução
}

O planejamento ambiental é uma ferramenta que visa à adequação do uso, controle e proteção ao ambiente natural, além do atendimento das aspirações sociais, econômicas e governamentais. Esse planejamento necessita de estudos aprofundados no local a ser desenvolvido, evidenciando a realidade do estado atual do ambiente e a pressão ao qual está submetido, de modo a revelar como a sociedade se comporta para sua melhoria (SILVA, 2003; SANTOS, 2004).

No Brasil, a Lei 9.985/00 institui o Sistema Nacional de Unidades de Conservação (SNUC), dando amparo legal e definindo diretrizes para a 
implantação e gestão das Unidades de Conservação (UCs). De acordo com Art. $2^{\circ}$ (BRASIL, 2000), uma UC é um "espaço territorial e seus recursos ambientais, incluindo as águas jurisdicionais, com características naturais relevantes".

Para Medeiros et al. (2011), espaços protegidos como as UCs são reconhecidos mundialmente como instrumentos fundamentais à preservação de espécies e ecossistemas, contendo os sistemas e meios tradicionais de sobrevivência das comunidades humanas, gozando assim, de estatuto legal e regime de administração diferenciados. Segundo a Lei Federal 9.985/00 e Benatti (2009), as UCs, embora criadas pelo poder público, podem ser públicas ou privadas. Além disso, podem ter ou não proteção integral e dependendo do tipo, ainda podem ser compatíveis com a presença de populações tradicionais em seu interior.

O uso de geotecnologias possibilita identificar e estabelecer um controle e/ou direcionamento das atividades antrópicas de uso da terra, avaliando os possíveis conflitos com suas aptidões e exigências legais. Visando preservar a biodiversidade, conservando áreas prioritárias com potencialidades ecológicas para tal, as geotecnologias têm sido utilizadas para direcionar ações do poder público (XIMENES et al., 2008). As geotecnologias têm contribuído para gerar resultados, favorecendo a tomada de decisão nas atividades de planejamento ambiental e auxiliando no desenvolvimento socioeconômico em equilíbrio ambiental dos municípios (FARINA, 2006; SAMIZAVA et al., 2008).

Ainda que seja possível identificar as características físicas do ambiente e realizar análises espaciais e temporais a partir da aplicação de geotecnologias, é importante ressaltar que o uso de dados obtidos por sensoriamento remoto e a análise espacial em Sistemas de Informações Geográficas (SIGs) apresentam limitações para avaliar as interações ecológicas existentes no ambiente. Desta forma, a probabilidade de sucesso de um diagnóstico visando à preservação aumenta quando é realizado em conjunto com uma análise ecológica da paisagem. 
O espaço natural é complexo e possui inúmeros fatores associados. Neste contexto, a tomada de decisão visando um planejamento ambiental coerente, e que envolva o ambiente natural, abrange um grande número de variáveis do meio biológico, físico, social e econômico. Neste sentido, a utilização de ferramentas de análise espacial facilita a tomada de decisão, pois permite reunir diversas variáveis, priorizando diferentes alternativas e atribuindo pesos às variáveis conforme seu grau de importância para o estudo. Sendo assim, a análise multicritério é um método de análise de alternativas para a solução de problemas que envolvem diversos fatores relacionados ao objeto de estudo, podendo identificar as alternativas prioritárias para o objetivo definido (FRANCISCO et al., 2007; FRANCO et al., 2013; LOCH et al., 2013).

O Vale do Taquari está inserido no Bioma da Mata Atlântica, considerado Patrimônio Nacional pela Constituição Federal de 1988. No ano de 1992, houve o tombamento da Mata Atlântica a nível Estadual, em 1994 houve a criação da Reserva da Biosfera da Mata Atlântica e, em 2006, houve a publicação da Lei Federal n ${ }^{\circ} 11.428$, que dispõe sobre a utilização e proteção da vegetação nativa do Bioma Mata Atlântica (BRASIL, 1988; CONSEMA, 1997; BRASIL, 2006).

Nesse contexto, o objetivo deste estudo é determinar os locais mais indicados para a implantação de unidades de conservação na região do Vale do Taquari, Rio Grande do Sul (RS), Brasil. Este estudo se refere a uma atualização e refinamento da pesquisa apresentada no trabalho de conclusão de Bianchini (2015), com alterações na base digital de remanescentes florestais e nos critérios utilizados para a seleção de áreas aptas para conservação, usando técnicas de geoprocessamento e análise multicritério. 


\section{Metodologia}

\section{1 Área de estudo}

A área de estudo compreende a região do Vale do Taquari, composta por 36 municípios e localizada no centro-leste do RS (Figura 1). A região apresenta uma área de $4.821 \mathrm{~km}^{2}$ e segundo o censo do Instituto Brasileiro de Geografia e Estatística (IBGE) em 2010, apresenta uma população de 327.723 habitantes, com 73\% de população urbana. A maioria dos municípios tem sua economia baseada na produção primária, principalmente na pequena propriedade rural familiar, caracterizando-se pela diversidade de culturas e criações. No entanto, alguns municípios apresentam maior desenvolvimento industrial e de serviços, como é o caso de Lajeado, Estrela, Taquari, Teutônia, Arroio do Meio e Encantado.

Figura 1 - Localização e identificação dos municípios que compreendem o Vale do Taquari, RS

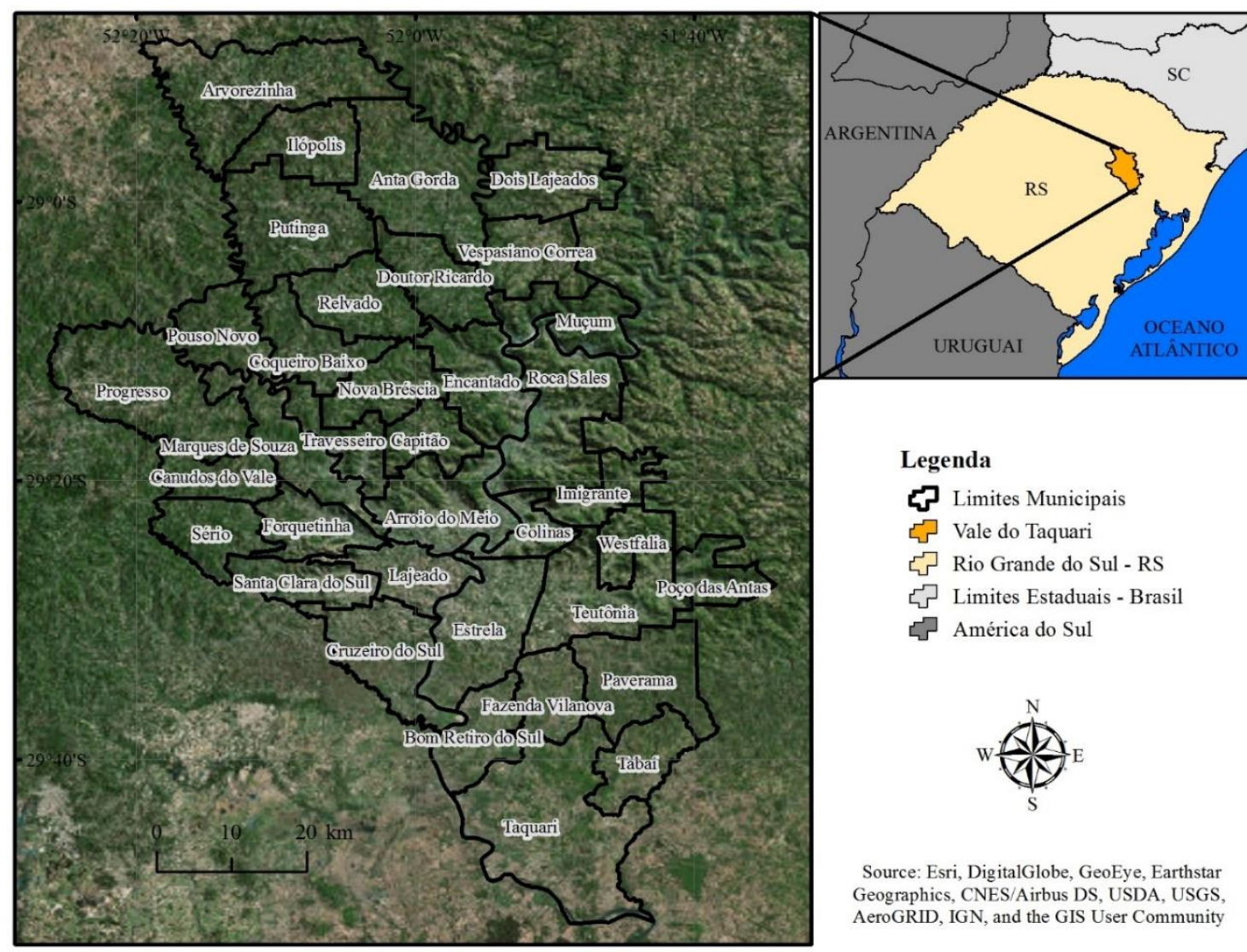

Fonte: Elaborada pelos autores. 
O Vale do Taquari está inserido na Bacia Hidrográfica do Rio TaquariAntas, tendo como principais rios o Taquari, o Guaporé e o Forqueta. Com base na Classificação Climática de Köppen, o clima da região é o subtropical úmido com verões quentes (Cfa) nas áreas mais baixas, e o subtropical úmido com verões amenos $(\mathrm{Cfb})$ na porção norte da área em função da altitude. $\mathrm{O}$ relevo apresenta grande amplitude altimétrica, sendo que mais de $43 \%$ da área apresenta relevo fortemente ondulado e montanhoso (ECKHARDT et al., 2007). As Unidades Geomorfológicas predominantes são: a) a Serra Geral, os Patamares da Serra Geral, e os Campos Gerais, as quais compõem as terras mais altas localizadas na porção centro-norte da área de estudo; b) a Depressão Central Gaúcha e os Terraços Aluviais, que se distribuem na porção sul, estando mais modificada pela ação antrópica (REMPEL, 2009). O bioma é o da Mata Atlântica, predominando a Floresta Estacional Decidual e Floresta Ombrófila Mista. A Mata Atlântica vem sofrendo com a pressão antrópica e atualmente está reduzida a 7\% da cobertura original, com poucas áreas protegidas por UCs. A redução do bioma é causada pelo desmatamento devido aos processos de urbanização, industrialização e expansão das atividades agropecuárias. Essa pressão tem causado uma enorme fragmentação do bioma, o que ameaça a diversidade biológica (MMA, 2002; VASCONCELLOS, 2002; SOSMA, 2013).

\subsection{Material e métodos}

Para o desenvolvimento do estudo foram utilizadas: a) a base cartográfica vetorial do Rio Grande do Sul, na escala 1:50.000, do Serviço Geográfico do Exército (DSG), digitalizada por Hasenack e Weber (2010); b) a base digital de remanescentes da Mata Atlântica (SOSMA, 2017), desenvolvida pela Fundação SOS Mata Atlântica em parceria com o Instituto Nacional de Pesquisas Espaciais (INPE).

O estudo dos locais mais indicados para conservação ambiental envolveu uma série de processamentos com bases georreferenciadas, que 
foram desenvolvidas no SIG ArcGIS 10.3. A Figura 2 apresenta as etapas de desenvolvimento da metodologia utilizada, que se baseia na análise multicritério de variáveis importantes para a conservação da natureza, com uso de geotecnologias e álgebra de mapas para definição dos locais aptos.

Figura 2 - Fluxograma das etapas da metodologia apresentada no presente estudo

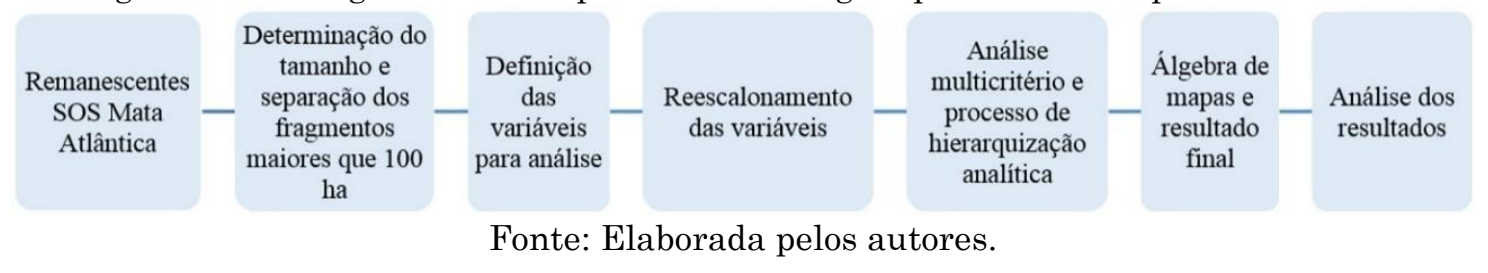

Inicialmente, foi definido um recorte espacial ampliado, por meio de um buffer de $10 \mathrm{~km}$ a partir dos limites da região, para evitar o efeito de borda nas análises espaciais. Após, utilizando-se a base de remanescentes da Mata Atlântica, foi determinado o tamanho dos fragmentos florestais e realizada a seleção daqueles que apresentavam área igual ou maior que 100 ha.

\subsubsection{Seleção das variáveis}

Neste trabalho, foram selecionadas sete variáveis de entrada visando a determinação de áreas prioritárias para a conservação ambiental. A escolha de tais variáveis se deu com base em pesquisa bibliográfica, como nos trabalhos de Bessa Junior e Müller (2000), Valente (2005), Sartori et al. (2012) e Freitas et al. (2013).

A primeira variável escolhida foi o tamanho do fragmento (TAM). Segundo Rimbaldi e Oliveira (2003), os fragmentos maiores são geralmente mais importantes para a conservação do que os pequenos fragmentos, visto que podem manter populações viáveis de plantas e os processos ecológicos com maior eficiência. Fragmentos pequenos podem não suprir as necessidades de espécies que necessitam de áreas maiores para seus movimentos e sua alimentação. Segundo Odum (1988), Almeida (2008) e SOSMA (2013), o TAM interfere na circulação de nutrientes através da paisagem e a distribuição e 
quantidade de espécies, afetando diretamente a sobrevivência de espécies da flora e da fauna, uma vez que, quanto menor for o fragmento, maior será a interferência dos fatores externos.

A segunda variável selecionada foi um índice de densidade de florestas (DFL). Esse índice foi obtido por meio do uso de operadores espaciais de cálculo de densidade de pontos. Os fragmentos florestais, polígonos em formato vetorial, foram transformados para uma matriz (raster). Em seguida, cada elemento da matriz (pixel) de floresta foi convertido para um vetor de pontos. Utilizando-se o SIG, foi gerada uma imagem com o número de pontos de florestas em um raio de $600 \mathrm{~m}$. Para cada fragmento, foi calculado o índice médio de densidade de florestas, por meio de ferramentas de estatísticas zonais.

A utilização da DFL buscou identificar fragmentos que apresentam menor interferência das atividades antrópicas no seu interior. Franco et al. (2007) encontraram maior número de espécies finais de sucessão ecológica, além das espécies comuns encontradas nas bordas e clareiras, nos fragmentos mais conservados. Alves e Metzger (2006) comentam que a presença de espécies finais de sucessão ecológica nos remanescentes é indispensável para a manutenção da diversidade biológica regional, visto que o enriquecimento e o avanço sucessional das florestas secundárias dependem da chegada de propágulos das espécies finais de sucessão presentes nessas "ilhas" de floresta primária (SILVA et al., 2005).

A terceira variável escolhida se refere à declividade (DEC). A declividade acentuada está relacionada à dificuldade de utilizar equipamentos na agricultura. Essa dificuldade acaba gerando um abandono das áreas e consequentemente uma regeneração das florestas. Silva et al. (2011) evidenciaram esse aumento da regeneração das florestas devido ao abandono das áreas antes ocupadas pelo setor agropecuário no município de Roca Sales, RS. Para identificar as declividades médias de cada fragmento, gerou-se um Modelo Digital do Terreno (MDT) a partir das curvas de nível e pontos cotados da base cartográfica vetorial contínua da DSG. O método de 
interpolação utilizado foi o inverso do quadrado da distância. A partir do MDT foram extraídas as declividades e calculados os valores médios em cada fragmento.

A quarta variável foi o índice de forma (IFO). A forma de um fragmento está relacionada à relação perímetro/área. Quanto menor for esta relação, menor será a borda, ou seja, maior será a área central que é a área efetivamente preservada e mais similar à vegetação original da região (MMA, 2002). Segundo Almeida (2008), o aumento da quantidade de borda pode comprometer diversos processos ecológicos, inclusive a existência de espécies animais e vegetais na área preservada. A mesma autora ainda sugere que o efeito de borda favorece o estabelecimento de espécies mais generalistas.

O cálculo do IFO (Equação 1) leva em conta o perímetro $(P)$ do fragmento e a área $(A)$ do mesmo, sendo que o índice de forma resulta em valores iguais ou maiores que 1 . Os fragmentos que possuem formatos circulares, apresentam valores próximos a 1 e possuem menor efeito de borda. Quanto maior o valor obtido, maior é a complexidade da forma do fragmento, indicando um grande perímetro e maior efeito de borda. Para gerar o IFO dos fragmentos foi utilizado o conjunto de ferramentas Patch Analyst, do ArcGIS. Com o arquivo dos fragmentos florestais, precedeu-se a análise do Mean Shape Index (MSI) do Spatial Statistics.

$$
\mathrm{IFO}_{\mathrm{i}}=\frac{\mathrm{P}_{\mathrm{i}}}{2 \sqrt{\pi \mathrm{A}_{\mathrm{i}}}}
$$

em que: $I F O_{i}$ é o índice de forma do fragmento $i$; $P$ é o perímetro; $A$ é a área.

A quinta variável escolhida se refere à distância das rodovias (DRO), pois estão relacionadas a restrições ao ambiente nas áreas adjacentes. Elas também são responsáveis pelo processo de fragmentação e geram significativos impactos removendo a cobertura vegetal, ocasionando o efeito de borda. As rodovias têm efeito de barreira artificial, reduzem a diversidade genética, aumentam as chances de dispersão de espécies exóticas e acarretam sérios impactos à fauna, favorecendo a elevação do índice de mortalidade. A travessia de animais pelas rodovias está relacionada a diversos fatores, 
apresentando a esses animais riscos de atropelamento. O prejuízo à fauna é mais acentuado quando existem rodovias nas proximidades de unidades de conservação (MILLI e PASSAMANI, 2006; PRADO et al., 2006). Segundo Scoss (2002), as estradas afetam negativamente espécies que não se adaptam bem a áreas com efeito de borda, espécies que são incapazes de atravessar estradas, que são sensíveis ao contato com os seres humanos e que procuram estradas para se aquecer ou em busca de alimento.

Para gerar o mapa de DRO utilizou-se a base de malha viária da DSG. O cálculo de distância foi realizado em uma grade regular, em que cada pixel apresenta a sua distância da rodovia mais próxima. Após, foi extraída a distância média de cada fragmento às rodovias usando a ferramenta de estatística zonal.

A sexta variável selecionada refere-se à distância das áreas urbanas (DAU). Essa variável condiciona restrições ao ambiente, relacionadas à pressão que as concentrações ou núcleos habitacionais exercem sobre o ambiente natural. Segundo Rimbaldi e Oliveira (2003), a urbanização está entre os fatores que desencadearam uma intensa devastação das florestas nativas. As áreas urbanas foram identificadas utilizando-se uma base de áreas urbanas disponibilizada pela Fundação SOS Mata Atlântica. O cálculo de distância média de cada fragmento aos núcleos urbanos foi realizado com as mesmas ferramentas utilizadas para o cálculo de distância às rodovias.

Por último, a sétima variável selecionada foi a densidade de nascentes (DNA). Segundo Felippe (2009), no sistema hidrológico as nascentes correspondem ao mais importante elemento, visto que promovem a passagem da água subterrânea para a superfície. Segundo o mesmo autor, elas dão início aos canais de drenagem sendo responsáveis pela porção dos recursos hídricos mais utilizada pela população e pela fauna. A importância das nascentes é reconhecida pela Lei Federal $\mathrm{n}^{\circ} 12.651 / 12$, que estabelece um raio de $50 \mathrm{~m}$ em seu entorno como Área de Preservação Permanente (BRASIL, 2012). Para gerar a densidade de nascentes em cada fragmento, utilizou-se a malha hidrográfica da DSG. Para cada fragmento, foi calculada a densidade média 
de nascentes, com as mesmas ferramentas utilizadas para o cálculo de densidade de florestas.

\subsubsection{Reescalonamento das variáveis}

O reescalonamento das variáveis consiste em aplicar transformações adequadas em cada uma das variáveis selecionadas, de modo que todas tenham a mesma ordem de grandeza. Isto é um pré-requisito da técnica AHP, de forma que os pesos relativos a cada uma das variáveis envolvidas sejam devidamente calculados. Neste estudo, optou-se por definir o valor 0 como mínimo e o valor 100 para a aptidão máxima em relação à escolha do local para conservação. Assim, todas as variáveis envolvidas possuem valores de aptidão $0 \leq$ val $\leq 100$.

No reescalonamento da variável TAM foi considerado que a aptidão é crescente à medida que aumenta o tamanho do fragmento. A regra escolhida se refere à função de crescimento linear (Figura 3A). Essa regra foi utilizada também para o reescalonamento dos valores de DFL, DNA e DEC. Em relação à variável IFO, foi considerada uma tendência linear decrescente (Figura 3B), isto é, com a aptidão máxima para IFO igual a 1 (fragmento circular, com menor efeito de borda), e aptidão mínima para o maior valor obtido nos fragmentos (formas alongadas ou irregulares). Já no reescalonamento das variáveis DRO e DAU, foi utilizada uma função sigmoide com aumento da aptidão à medida que aumenta a distância média do fragmento (Figura 3C), considerando aptidão máxima (100) quando a distância das rodovias é maior que $1 \mathrm{~km}$ e das áreas urbanas quando é maior que $10 \mathrm{~km}$. 
Figura 3 - Funções utilizadas para o reescalonamento das variáveis
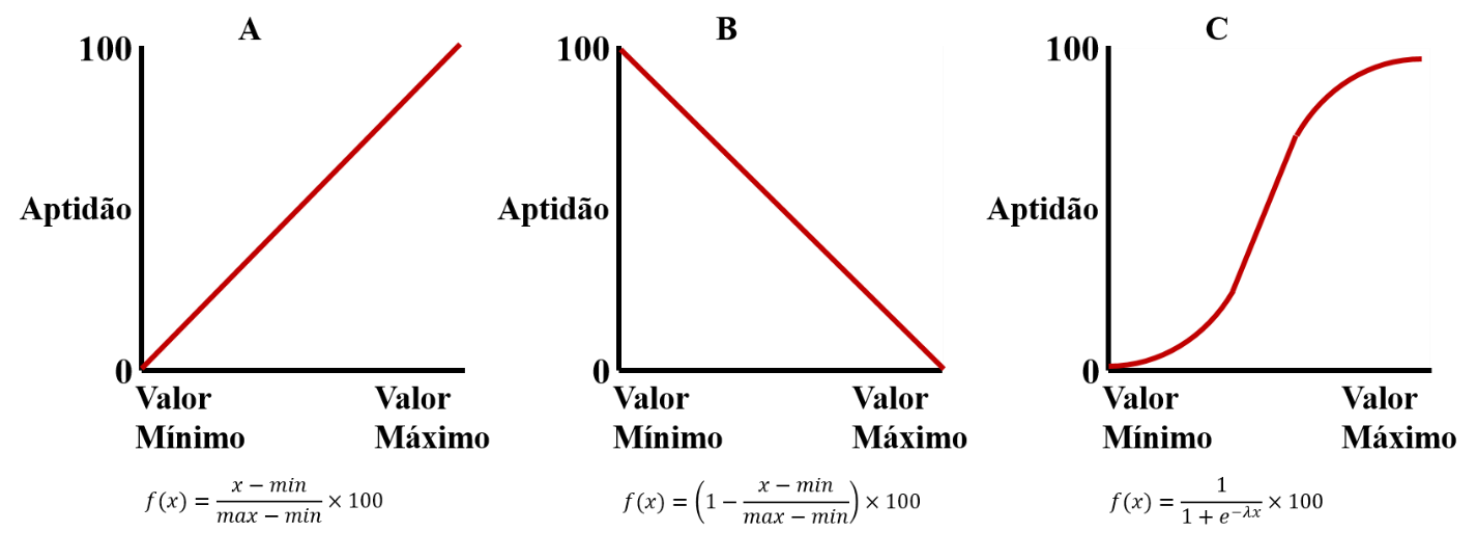

Fonte: Elaborada pelos autores.

\subsubsection{Processo analítico hierárquico}

O processo analítico hierárquico, denotado de AHP, foi proposto por Saaty (1977). Trata-se de uma técnica de escolha baseada na lógica da comparação pareada, na qual os diferentes fatores (variáveis) que influenciam a tomada de decisão são comparados dois-a-dois. Um critério de importância relativa é atribuído ao relacionamento entre os fatores, conforme uma tabela pré-definida. Uma vez estabelecido o grau de importância entre os fatores, imposto pelo especialista, é de fundamental importância verificar a consistência de seu julgamento. Isto é realizado por meio do cálculo do índice de consistência, que não deve superar o valor de 0,1. Por fim, os pesos (influência) de cada um dos fatores envolvidos são determinados (DIAS e SILVA, 2014).

Neste trabalho, a técnica AHP foi aplicada individualmente por seis especialistas: dois biólogos, dois geógrafos, um geólogo e um engenheiro ambiental. Em cada uma das análises foi verificado o índice de consistência, e posteriormente os pesos foram determinados de modo mais abrangente em relação às respectivas áreas de conhecimento.

A saída AHP foi submetida à álgebra de mapas pela Equação 2. Neste trabalho, optou-se pelo cálculo da média dos pesos obtidos, em cada uma das seis matrizes AHP preenchidas, para cada variável reescalonada. Assim, 
foram realizados os cálculos para a determinação das áreas mais indicadas para implantação das UCs, resultando em um mapa de ordenamento contendo os fragmentos com maior aptidão.

$$
\mathrm{APT}_{\mathrm{i}}=\sum \mathrm{Z}_{\mathrm{ij}} \overline{\mathrm{W}}_{\mathrm{ij}}
$$

em que: $A P T_{i}$ é a aptidão do $i$-ésimo fragmento para a implantação de uma unidade de conservação; $Z_{i j}$ é o valor reescalonado da $j$-ésima variável para o $i$-ésimo fragmento; $\bar{W}_{i j}$ é o peso médio relativo à $j$-ésima variável para o $i$ ésimo fragmento.

\section{Resultados e discussões}

A identificação dos fragmentos maiores ou iguais a 100 ha resultou na seleção de 235 fragmentos (Figura 4). Apenas 13 fragmentos possuem área superior a 1.000 ha. A maior parte dos fragmentos está localizada em áreas de encosta, criando um cinturão de florestas na escarpa erosiva da Serra Geral e nos vales fluviais mais íngremes. Esse padrão espacial pode ser explicado por que as áreas com declividade mais acentuada apresentam dificuldades de acesso para a agricultura mecanizada, sofrendo retração da agricultura nas últimas décadas e, consequentemente, um aumento na regeneração das florestas.

Na Figura 5 é apresentado um gráfico do tipo boxplot com a tendência central e a dispersão dos valores de cada uma das sete variáveis analisadas em relação a cada fragmento florestal. Nesse gráfico, pode-se confirmar alguns resultados relevantes: a) os fragmentos tendem a possuir pequenas dimensões, normalmente inferiores a 500 ha, indicando um elevado grau de fragmentação da paisagem no Vale do Taquari; b) a maior parte das áreas de vegetação possui declividades acentuadas, predominando o intervalo entre 15 e $25^{\circ}$; c) o índice de forma indica que os fragmentos florestais tendem a possuir um perímetro extenso, com maior efeito de borda, com a maior parte das amostras entre 2 e 4 ; d) a maior parte das áreas de florestas apresenta uma 
distância média considerável de rodovias (maioria entre 300 e 600 m) e núcleos urbanos (maioria entre 3 e $7 \mathrm{~km}$ ), sendo um indicador importante para reduzir os impactos provocados pelas atividades humanas e tráfego de veículos; e) o indicador de densidades de nascentes mostra que a grande maioria dos fragmentos de floresta possui até duas nascentes por $\mathrm{km}^{2}$.

Figura 4 - Mapa dos fragmentos florestais com área igual ou maior que 100 ha no Vale do Taquari

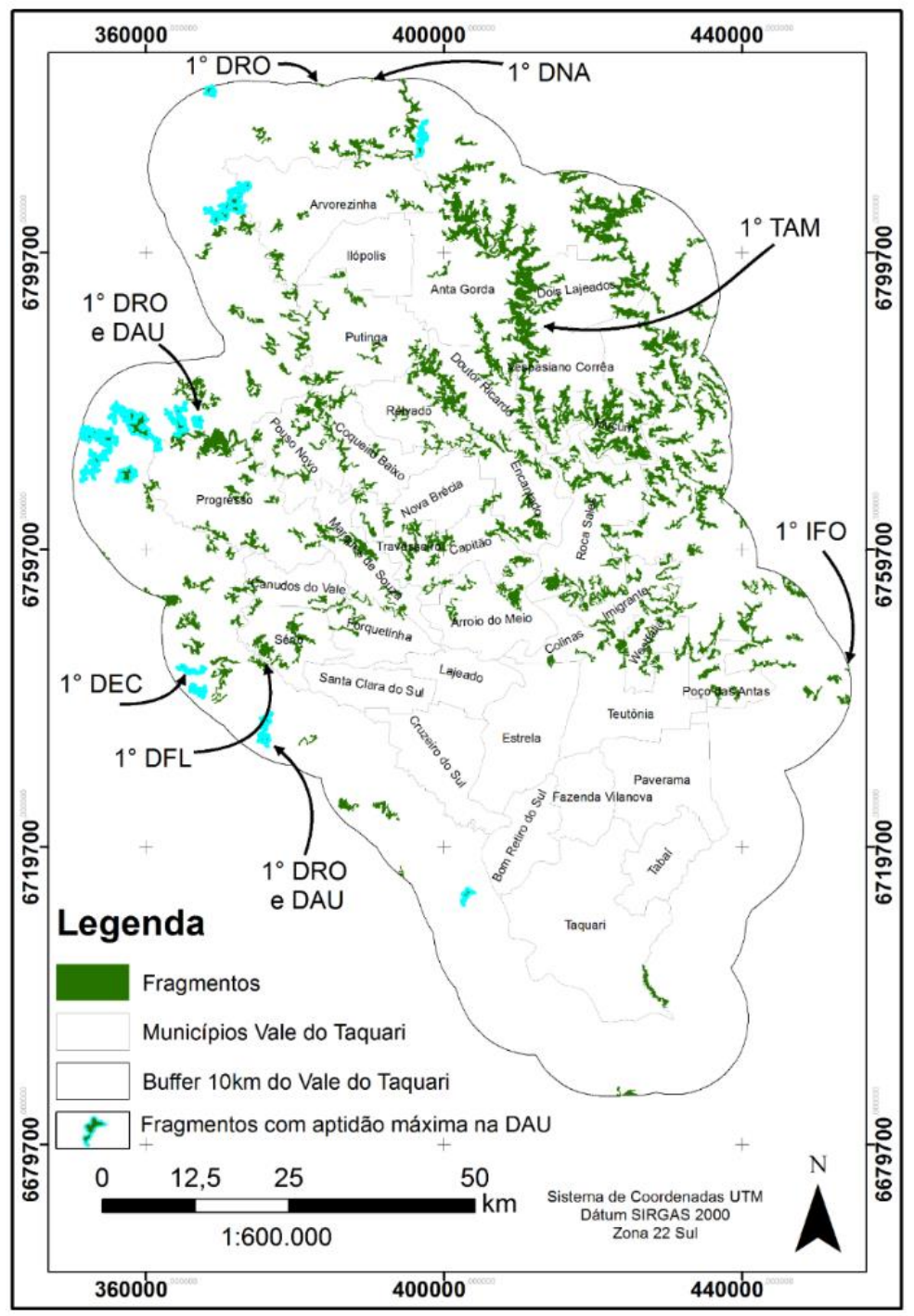

Fonte: Elaborada pelos autores. 
Figura 5 - Gráfico do tipo boxplot dos valores das variáveis explicativas em relação aos fragmentos florestais para transformação em unidade de conservação
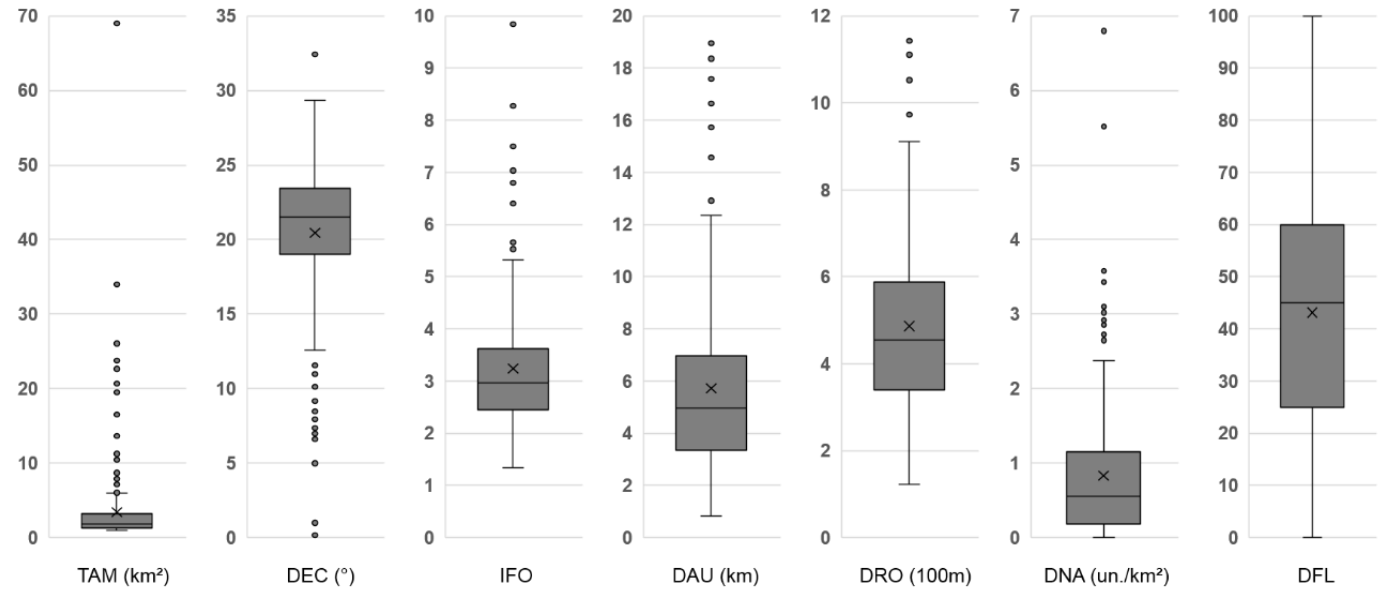

Fonte: Elaborada pelos autores.

Em seguida, as variáveis foram reescalonadas no intervalo de aptidão de 0 a 100, de acordo com as três funções apresentadas na metodologia, considerando o conjunto de fragmentos florestais. A maioria das variáveis apresentou somente um fragmento com a maior aptidão, sendo que o mesmo está indicado por uma seta na Figura 4.

As variáveis de distância média das rodovias e das áreas urbanas apresentaram mais de um fragmento com aptidão máxima. O fato de usar um limiar de distância, a partir da qual a aptidão fica igual a 100, sendo de $1 \mathrm{~km}$ para rodovias e de $10 \mathrm{~km}$ para áreas urbanas, fez com que estas variáveis apresentassem mais de um fragmento com aptidão máxima. Sendo assim, obteve-se três fragmentos com aptidão máxima para distância média das rodovias e 18 fragmentos com aptidão máxima para a distância média das áreas urbanas.

O fragmento florestal que apresentou a maior aptidão conforme o seu tamanho (TAM) foi o localizado entre os Municípios de Dois Lajeados e Anta Gorda, na porção norte do Vale do Taquari (Figura 4). Esse fragmento possui uma área de 6.902 ha e se destaca de modo positivo também em outros indicadores: a) declividades, com média de $21^{\circ}$ (aptidão de 65 pontos), b) distância das áreas urbanas, com média de 6,8 km (aptidão de 64 pontos), c) distância das rodovias, com média $440 \mathrm{~m}$ (aptidão de 63 pontos). 
Considerando as variáveis analisadas, duas desvantagens dessa área para conservação se referem à forma do fragmento (mais irregular, com IFO igual a 9,8, aptidão 0) e à densidade de nascentes $\left(0,14\right.$ nascentes por $\mathrm{km}^{2}$, aptidão $2)$.

O fragmento localizado na porção oeste do Vale do Taquari, no município de Sério, apresentou a maior aptidão para a densidade de florestas, em função dos poucos vazios (pixels sem floresta) no interior do fragmento (Figura 4). Essa área de floresta apresentou boas aptidões para as variáveis de declividades (média de $28^{\circ}$, aptidão 85 ), de índice de forma (IFO igual a 2,7, aptidão 84) e de distância das rodovias (média de $734 \mathrm{~m}$, aptidão 81). No entanto, esse fragmento florestal apresentou baixas aptidões para as variáveis de densidades de nascentes (0,26 nascentes por $\mathrm{km}^{2}$, aptidão 4), de tamanho (445 ha, aptidão 5) e de distância das áreas urbanas (média de 2,1 km, aptidão 13).

A área de floresta que apresentou a maior aptidão para a declividade média está localizada no limite do Vale do Taquari, no extremo oeste da área de estudo. Esse fragmento apresenta uma declividade média de $32^{\circ}$. Esse fragmento se destaca positivamente também em relação à distância das áreas urbanas (média de 11,7 km, aptidão 100), ao índice de forma (IFO igual a 2,5, aptidão 86) e à densidade de florestas (aptidão 61). Por outro lado, apresentou baixos índices de aptidão em relação ao tamanho do fragmento (168 ha, aptidão 1) e à densidade de nascentes ( 0,88 nascentes por $\mathrm{km}^{2}$, aptidão 13$)$.

$\mathrm{O}$ fragmento com a maior aptidão para a variável de índice de forma, com IFO igual a 1,3, está localizado no limite do Vale do Taquari, no extremo leste da área de estudo. Pode-se perceber que na maioria dos fragmentos que apresentaram áreas elevadas, tiveram índice de forma igualmente elevado, representando baixas aptidões para esta variável, pois, geralmente grandes fragmentos apresentam bordas irregulares. Este fragmento, no geral, apresentou baixas aptidões (inferior a 33 pontos) para as outras variáveis, com exceção da declividade média de $20^{\circ}$ (aptidão 62). 
A aptidão para distância média das rodovias apresentou três fragmentos com pontuação máxima, ou seja, com distância média das rodovias superior a $1 \mathrm{~km}$. Uma área de floresta com essa característica está localizada na porção sudoeste da área de estudo, no limite do Vale do Taquari, no município de Venâncio Aires (Figura 4). Esse fragmento florestal também possui a máxima aptidão para a distância média das áreas urbanas, além de bons índices em relação à forma (IFO igual a 2,97, aptidão 81) e à densidade de florestas (aptidão 75). Um segundo fragmento também apresentou pontuação máxima em relação à distância de rodovias e áreas urbanas, estando localizado na porção noroeste da área de estudo, no município de Fontoura Xavier, às margens do Rio Fão. Essa área de floresta também apresentou boa aptidão em relação ao índice de forma (IFO igual a 2,2, aptidão 90) e às declividades (média de $23^{\circ}$, aptidão 72 ). Já o terceiro fragmento que apresentou pontuação máxima na aptidão para a variável de distância média das rodovias está localizado ao norte da área de estudo, obtendo também bons índices em relação à forma (IFO igual a 1,85, aptidão 94) e à distância de áreas urbanas (média de 6,5 km, aptidão 61).

A variável de distância média das áreas urbanas apresentou 18 fragmentos com aptidão máxima, ou seja, com distância média superior a 10 $\mathrm{km}$ de áreas urbanas. Conforme pode ser observado na Figura 4, os fragmentos com borda destacada na cor ciano são os fragmentos que apresentaram aptidão máxima para esta variável. A maior parte dessas áreas florestais se referem a fragmentos de pequena dimensão e localizados próximos aos limites da área de estudo.

$\mathrm{O}$ fragmento que apresentou a maior aptidão quanto à densidade de nascentes se refere a uma área de floresta localizada no extremo norte da área de estudo, com densidade de 6,8 nascentes por $\mathrm{km}^{2}$. Além desse índice, o fragmento apresenta boa aptidão em relação à forma (IFO igual a 2,2, aptidão 90) e à distância de áreas urbanas (média de $8,2 \mathrm{~km}$, aptidão 80).

Após o reescalonamento, foram obtidos os pesos (influência) das variáveis na determinação de áreas para conservação, de acordo com o 
julgamento de cada especialista consultado, a partir do método AHP (Tabela 1). Os pesos expressos na coluna com a média geral representam a contribuição de cada parâmetro para a determinação dos locais mais indicados para implantação de UCs no Vale do Taquari.

Tabela 1 - Resultados da AHP pelos especialistas e a média geral dos pesos atribuídos

\begin{tabular}{|c|c|c|c|c|c|c|c|}
\hline \multirow[b]{2}{*}{ Variáveis } & \multicolumn{6}{|c|}{ Pesos por especialista } & \multirow[b]{2}{*}{$\begin{array}{l}\text { Média } \\
\text { Geral }\end{array}$} \\
\hline & $\begin{array}{c}\text { Biólogo } \\
1\end{array}$ & $\begin{array}{c}\text { Biólogo } \\
2\end{array}$ & $\begin{array}{c}\text { Geógrafo } \\
1\end{array}$ & $\begin{array}{c}\text { Geógrafo } \\
2\end{array}$ & Geólogo & $\begin{array}{c}\text { Eng. } \\
\text { Ambiental }\end{array}$ & \\
\hline TAM & 0,40 & 0,22 & 0,35 & 0,19 & 0,35 & 0,21 & 0,28 \\
\hline DFL & 0,23 & 0,22 & 0,19 & 0,37 & 0,25 & 0,15 & 0,23 \\
\hline DEC & 0,07 & 0,07 & 0,02 & 0,03 & 0,11 & 0,15 & $\mathbf{0 , 0 8}$ \\
\hline IFO & 0,09 & 0,28 & 0,19 & 0,19 & 0,15 & 0,05 & 0,16 \\
\hline DRO & 0,04 & 0,03 & 0,06 & 0,07 & 0,03 & 0,13 & 0,06 \\
\hline DAU & 0,03 & 0,03 & 0,05 & 0,07 & 0,03 & 0,12 & 0,05 \\
\hline DNA & 0,14 & 0,16 & 0,14 & 0,08 & 0,09 & 0,19 & 0,14 \\
\hline Somatório & 1,00 & 1,00 & 1,00 & 1,00 & 1,00 & 1,00 & 1,00 \\
\hline $\begin{array}{c}\text { Índice de } \\
\text { Consistência } \\
\text { AHP }\end{array}$ & 0,03 & 0,06 & 0,02 & 0,02 & 0,05 & 0,03 & 0,04 \\
\hline
\end{tabular}

Fonte: Elaborada pelos autores.

Analisando-se os resultados apresentados na Tabela 1, é possível perceber que os especialistas tiveram opiniões um pouco diferentes em determinadas variáveis. Percebe-se que em alguns casos a diferença foi mais que o dobro do peso para a mesma variável, como é o caso do tamanho do fragmento, que variou de 0,19 até 0,40.

O tamanho dos fragmentos foi a variável que recebeu o maior peso médio, com valor de 0,28 na média geral, sendo que quatro dos seis especialistas atribuíram o maior peso entre as variáveis para essa categoria. A segunda variável a receber maior importância foi a densidade de florestas, com peso de 0,23. Em terceiro em importância, foi o índice de forma com peso de 0,16 , seguido pela densidade de nascentes com 0,14.

A álgebra de mapas, com o somatório do produto entre os pesos mencionados acima com suas respectivas variáveis reescalonadas (de 0 a 100), resultou em um mapa apresentando os valores de aptidão de cada fragmento de floresta. A aptidão final dos 235 fragmentos variou de 21,3 a 53,2 pontos, em uma escala possível de 0 a 100. 
Na Figura 6 é apresentado o mapa final de aptidão para a implantação de Unidades de Conservação no Vale do Taquari, RS. O fragmento que apresentou a maior pontuação geral de aptidão (53 pontos) se refere a uma área de floresta localizada na porção central do Vale do Taquari, no nordeste do município de Arroio do Meio ( $\left.1^{\circ}\right)$, conforme indicado na Figura 6. A porção sudeste deste fragmento é bastante conhecida da comunidade da região, trata-se do Morro Gaúcho.

Figura 6 - Aptidão geral dos fragmentos mais indicados para implantação de UC no Vale do Taquari

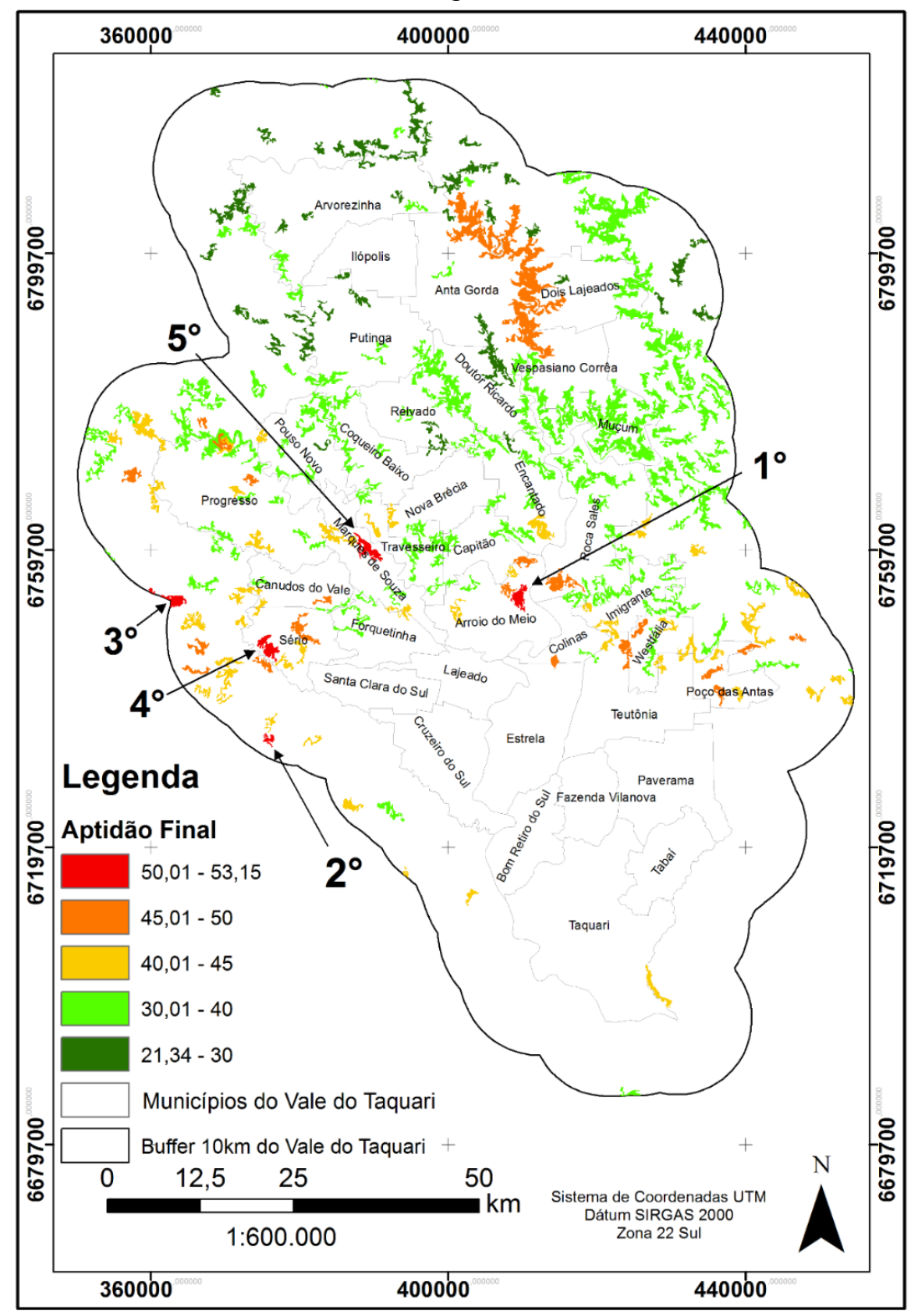

Fonte: Elaborada pelos autores. 
Essa área florestal, embora apresente baixa aptidão em relação à dimensão (373 ha, com aptidão 4), conta com uma elevada densidade de florestas (aptidão 93), com um índice de forma igual a 2,9 (aptidão 82), uma boa distância média de rodovias (603 m, aptidão 77) e uma declividade média de $22^{\circ}$ (aptidão 66).

A segunda área florestal com maior índice geral (52 pontos) se refere ao fragmento localizado em Venâncio Aires $\left(2^{\circ}\right)$, no limite do Vale do Taquari, porção extrema sudoeste da área de estudo, que obteve aptidão máxima em relação à distância às rodovias e áreas urbanas, conforme já mencionado anteriormente. $\mathrm{O}$ que pesou negativamente na avaliação dessa área é a sua dimensão, com apenas 127 ha.

Outros fragmentos que podem ser destacados estão localizados nos municípios de Canudos do Vale ( $3^{\circ}$ em aptidão geral), Sério ( $\left.4^{\circ}\right)$ e de Marques de Souza $\left(5^{\circ}\right)$, todos na porção centro-oeste do Vale do Taquari, na escarpa erosiva do planalto. A aptidão geral dessas áreas de florestas é semelhante aos dois fragmentos anteriores, com valores na ordem de 50 no índice. Essas três áreas de floresta se destacam positivamente pela densidade de florestas, forma do fragmento, declividades e distância média das rodovias.

Os fragmentos que apresentaram as menores aptidões estão localizados na região norte do Vale do Taquari. A maioria deles apresenta pequeno tamanho, baixa densidade de florestas, formatos bastante irregulares e também baixas declividades. O fragmento que apresentou a menor aptidão, está localizado na divisa do município de Arvorezinha com Itapuca, já fora dos limites do Vale do Taquari.

A utilização de geotecnologias facilita e agiliza o trabalho de identificação dos melhores locais para implantação de UCs, devido à quantidade de informações tratadas e a rapidez no desenvolvimento da pesquisa. No entanto, somente o levantamento das informações físicas não garante uma boa escolha quando se trata de UCs. Devido à complexidade e a dificuldade em se avaliar diversos locais com aptidão elevada para 
implantação de UCs na região, optou-se por avaliar aspectos adicionais de somente um local, a escolha recaiu sobre o local com maior pontuação de aptidão.

O fragmento que apresentou a maior aptidão já foi utilizado para desenvolvimento de trabalhos de pesquisa. Dentre os trabalhos, pode-se citar: Leuchtenberger (2005), que realizou uma caracterização e um diagnóstico ambiental do Morro Gaúcho, também com o objetivo de implantação de uma UC; Krüger (2008), que realizou um trabalho sobre ecoturismo e sustentabilidade no Vale do Taquari e as possibilidades a partir do estudo de caso no Morro Gaúcho em Arroio do Meio, e; Thomas (2013), que realizou estudo para delimitar uma UC como subsídio à sua criação, tendo essa área como objeto de estudo.

O local também é procurado por observadores de aves desde o início dos anos 2000 e com maior intensidade nos últimos anos. As observações mais recentes têm sido realizadas pelo Clube de Observadores de Aves dos Vales do Taquari e Rio Pardo (COA Vales), do qual, o autor deste estudo também é integrante. No ano de 2015 o autor realizou um levantamento no local e registrou a ocorrência de 128 espécies de aves em apenas 12 horas de trabalho de campo. No entanto, este número é ainda maior quando considerados os registros realizados pelo COA Vales e publicados no sítio eletrônico WIKIAVES (WIKIAVES, 2016).

Os estudos anteriormente citados apontaram a ocorrência de inúmeras espécies da flora e fauna, diversas com algum grau de ameaça de extinção. Também houve a constatação da importância do local devido suas características paisagísticas e significativa biodiversidade por parte da comunidade local e regional. Além da identificação de ameaças com caça, extração ilegal de palmito e ocupação desordenada. Todos estes fatores foram base para a sugestão da criação de uma Área de Relevante Interesse Ecológico (ARIE) na porção mais preservada do Morro Gaúcho por Thomas (2013).

Desta forma, o presente trabalho corrobora com o que já havia sido constatado nesses estudos, de que a área do Morro Gaúcho apresenta 
elementos favoráveis à implantação de uma Unidade de Conservação. A utilização de técnicas de geoprocessamento, combinadas à seleção adequada de variáveis espaciais e critérios para o peso dessas variáveis no mapa final, resultou em uma representação espacial que pode ser utilizada para a determinação de áreas prioritárias à conservação do meio ambiente, podendo a mesma metodologia ser testada e adaptada para outras regiões do Brasil.

\section{Conclusões}

O presente estudo realizou uma análise de diversas variáveis para encontrar as melhores áreas para implantação de UCs no Vale do Taquari, considerando informações espaciais em um SIG.

A utilização de geotecnologias para a pré-seleção de áreas florestais para implantação de UCs constitui-se em uma importante ferramenta de planejamento ambiental, pois o SIG, juntamente com as técnicas de geoprocessamento, facilita e agiliza a manipulação de grande quantidade de informações espaciais. Além disso, os SIGs dispõem de inúmeras ferramentas de análise de dados georreferenciados, o que possibilita a extração de índices de aptidão para a implantação de diversos empreendimentos e/ou projetos.

A análise multicritério, baseada no processo analítico hierárquico, possibilitou a escolha e a determinação dos pesos de forma mais imparcial, visto que foram consultados especialistas de quatro áreas de formação. De maneira geral, a metodologia proposta possibilitou atingir o objetivo estipulado nesse trabalho.

No total, foram extraídos 235 fragmentos de vegetação e as variáveis analisadas em cada fragmento com seus respectivos pesos foram: o tamanho dos fragmentos $(0,28)$, densidade de florestas $(0,23)$, declividade média $(0,08)$, índice de forma $(0,16)$, distância média das rodovias $(0,06)$ e das áreas urbanas $(0,05)$, e densidade de nascentes $(0,14)$.

$\mathrm{O}$ resultado indicou a maior aptidão para o fragmento de vegetação localizado no Morro do Gaúcho, uma área já reconhecida pela população e por 
agentes ambientais pela sua paisagem e importância ecológica para conservação. Essa área florestal, embora apresente baixa aptidão em relação à dimensão (373 ha), conta com uma elevada densidade de florestas, um índice de forma igual a 2,9, uma boa distância média de rodovias (603 m) e uma declividade média de $22^{\circ}$.

Deste modo, considerando os diversos estudos que destacam o Morro Gaúcho em relação à sua importância ecológica para a região do Vale do Taquari e, salientando que a metodologia aplicada neste estudo também indicou a mesma área com elevada aptidão, pode-se concluir que o uso das geotecnologias e da análise multicritério com a participação de profissionais de diferentes áreas da ciência obteve um resultado consistente em relação à pré-seleção de áreas para conservação. Mesmo com as limitações relacionadas à escala de mapeamento e à ausência de informações mais detalhadas do ponto de vista ecológico, a metodologia foi capaz de identificar áreas reconhecidas pela comunidade local como de interesse para a preservação ambiental.

No entanto, deve-se ressaltar a importância de levantamentos de campo para uma análise mais detalhada das principais áreas de florestas destacadas neste estudo, tendo em vista a complexidade e as interações ambientais nos fragmentos selecionados. Isso porque somente o levantamento das informações físicas em meio digital não garante uma boa escolha quando se trata de UCs.

\section{Agradecimentos}

Os autores agradecem a contribuição dos diferentes profissionais para o preenchimento da matriz AHP. 


\section{Contribuição dos autores}

O primeiro autor, Cleberton Diego Bianchini, foi o principal responsável pela revisão bibliográfica, reescalonamento das variáveis de entrada e elaboração dos mapas. O segundo autor, Guilherme Garcia de Oliveira, foi o principal responsável pela definição das variáveis e interpretação dos resultados da análise multicritério. A redação do artigo e discussão dos resultados foi realizada de forma conjunta, tendo igual participação dos dois autores.

\section{Referências}

ALMEIDA, C. G. Análise espacial dos fragmentos florestais na área do parque nacional dos Campos Gerais, Paraná. Dissertação de Mestrado. Universidade Estadual de Ponta Grossa, Programa Pós-Graduação em Gestão do Território: Sociedade e Natureza, Ponta Grossa, 2008. 74p.

ALVES, L. F.; METZGER, J. P. A regeneração florestal em áreas de floresta secundária na Reserva Florestal do Morro Grande, Cotia, SP. Biota Neotropica, vol. 6, n. 2, 2006. pp. 1-26.

BENATTI, J. H. Unidades de conservação e as populações tradicionais: uma análise jurídica da realidade Brasileira. Novos Cadernos NAEA, vol. 2, n. 2, 2009. pp. 107-125.

BESSA JUNIOR, O.; MÜLLER, A. C. P. Indicadores ambientais georreferenciados para a área de proteção ambiental de Guaraqueçaba. Revista Paranaense de Desenvolvimento, n. 99, 2000. pp. 105-119.

BIANCHINI, C. D. Determinação de áreas mais indicadas para implantação de unidades de conservação no Vale do Taquari - RS. Trabalho de Conclusão de Graduação. Universidade do Vale do Taquari, Graduação em Engenharia Ambiental, Lajeado, 2015. 129p.

BRASIL. Constituição Federal de 1988. Brasília, 1988. 
BRASIL. Lei Federal n 11.428, de 22 de dezembro de 2006. Dispõe sobre a utilização e proteção da vegetação nativa do Bioma Mata Atlântica, e dá outras providências. Brasília, Diário Oficial da União, 22 de dezembro de 2006.

BRASIL. Lei Federal n 12.651, de 25 de maio de 2012. Dispõe sobre a proteção da vegetação nativa; altera as Leis n 6.938, de 31 de agosto de 1981, 9.393, de 19 de dezembro de 1996, e 11.428, de 22 de dezembro de 2006; revoga as Leis $\mathrm{n}^{\circ}$ 4.771, de 15 de setembro de 1965, e 7.754, de 14 de abril de 1989, e a Medida Provisória $n^{\circ}$ 2.166-67, de 24 de agosto de 2001; e dá outras providências. Brasília, Diário Oficial da União, 25 de maio de 2012.

BRASIL. Lei Federal n 9.985 , de 18 de julho de 2000. Regulamenta o art. 225, $1^{\circ}$, incisos I, II, III e VII da Constituição Federal, institui o Sistema Nacional de Unidades de Conservação da Natureza e dá outras providências. Brasília, Diário Oficial da União, 18 de julho de 2000.

CONSEMA, Conselho Estadual de Meio Ambiente do Rio Grande do Sul. Resolução $\mathrm{n}^{\circ}$ 01, de 15 de setembro de 1997. Porto Alegre, Diário Oficial do Estado, 15 de setembro de 1997.

DIAS, V. S. B.; SILVA, A. D. B. AHP na modelagem da vulnerabilidade ambiental do mini corredor ecológico Serra das Onças (BA). Revista Brasileira de Cartografia, vol. 6, n. 66, 2014. pp. 1363-1377.

ECKHARDT, R. R.; REMPEL, C.; SALDANHA, D. L.; GUERRA, T.; PORTO, M. L. Análise e diagnóstico ambiental do Vale do Taquari - RS - Brasil, utilizando sensoriamento remoto e técnicas de geoprocessamento. Anais XIII Simpósio Brasileiro de Sensoriamento Remoto, Florianópolis, 2007. pp. 5191-5198.

FARINA, F. C. Abordagem sobre as técnicas de geoprocessamento aplicadas ao planejamento e gestão urbana. Cadernos EBAPE.BR, vol. 4, n. 4, 2006. pp. $1-13$.

FELIPPE, M. F. Caracterização e tipologia de nascentes em unidades de conservação de Belo Horizonte-MG com base em variáveis geomorfológicas, hidrológicas e ambientais. Dissertação de Mestrado. Universidade Federal de Minas Gerais, Programa de Pós-Graduação em Geografia e Análise Ambiental, Belo Horizonte, 2009. 275p.

FRANCISCO, C. E. S.; COELhO, R. M.; TORRES, R. B.; ADAMI, S. F. Espacialização de análise multicriterial em SIG: prioridades para recuperação 
de Áreas de Preservação Permanente. Anais XIII Simpósio Brasileiro de Sensoriamento Remoto, Florianópolis, 2007. pp. 2643-2650.

FRANCO, G. A. D. C.; SOUZA, F. M.; IVANAUSKAS, N. M.; MATTOS, I. F. A.; Baitello, J. B.; AGUiAR, O. T.; CATARUCCI, A. F. M.; POLISEL, R. T. Importância dos remanescentes florestais de Embu (SP, Brasil) para a conservação da flora regional. Biota Neotropica, vol. 7, n. 3, 2007. pp. 145161.

FRANCO, R. A. M.; HERNANDEZ, F. B. T.; MORAES, J. F. L. O uso da análise multicritério para a definição de áreas prioritárias a restauração de Área de Preservação Permanente (APP), no noroeste paulista. Anais XVI Simpósio Brasileiro de Sensoriamento Remoto, Foz do Iguaçu, 2013. pp. 3366-3373. FREITAS, E. P.; MORAES, J. F. L.; PECHE FILHO, A.; STORINO, M. Indicadores ambientais para áreas de preservação permanente. Revista Brasileira de Engenharia Agrícola e Ambiental, vol. 17, n. 4, 2013. pp. 443-449.

HASENACK, H.; WEBER, E. Base cartográfica vetorial contínua do Rio Grande do Sul - escala 1:50.000. Porto Alegre: UFRGS-IB-Centro de Ecologia, vol. 1, 2010.

KRÜGER, A. Ecoturismo e sustentabilidade no Vale do Taquari: possiblidades a partir do estudo de caso no Morro Gaúcho em Arroio do Meio. Dissertação de Mestrado. Universidade do Vale do Taquari, Programa de Pós-Graduação em Ambiente e Desenvolvimento, Lajeado, 2008. $169 \mathrm{p}$.

LEUCHTENBERGER, C. Caracterização de diagnóstico ambiental da região do Morro Gaúcho, Vale do Taquari, com vistas a implantação de uma Unidade de Conservação. Trabalho de Conclusão de Graduação. Universidade do Vale dos Sinos, Graduação em Ciências Biológicas Licenciatura, São Leopoldo, 2005. 68p.

LOCH, C.; REBOLLAR, P. B. M.; ROSENFELDT, Y. A. Z.; RAITZ, C. S.; OLIVEIRA, M. O. Definição de áreas para formação de corredores ecológicos através da integração de dados em um Sistema de Informação Geográfica. Revista Brasileira de Cartografia, vol. 65, n. 3, 2013. pp. 455-465. 
MEDEIROS, R.; YOUNG, C. E. F.; PAVESE, H. B.; ARAÚJO, F. F. S. Contribuição das unidades de conservação brasileiras para a economia nacional: Sumário Executivo. Brasília: UNEP-WCMC, 2011. 44p.

MILLI, M. S.; PASSAMANI, M. Impacto da Rodovia Josil Espíndula Agostini (ES259) sobre a mortalidade de animais silvestres (Vertebrata) por atropelamento. Natureza on line, vol. 4, n. 2, 2006. pp. 40-46.

MMA, Ministério do Meio Ambiente. Biodiversidade brasileira: avaliação e identificação de áreas e ações prioritárias para conservação, utilização sustentável e repartição dos benefícios da biodiversidade nos biomas brasileiros. Brasília: MMA/SBF - MINISTÉRIO DO MEIO AMBIENTE. SECRETARIA DE BIODIVERSIDADE E FLORESTAS, 2002. $404 \mathrm{p}$.

ODUM, E. P. Ecologia. Rio de Janeiro: Guanabara Koogan, 1988. 434p.

PRADO, T. R.; FERREIRA, A. A.; GUIMARÃES, Z. F. S. Efeito da implantação de rodovias no cerrado brasileiro sobre a fauna de vertebrados. Acta Scientiarum Biological Sciences, vol. 28, n. 3, 2006. pp. 237-241.

REMPEL, C. A ecologia da paisagem e suas ferramentas podem aprimorar o zoneamento ambiental? $O$ caso da região política do Vale do Taquari. Tese de Doutoramento. Universidade Federal do Rio Grande do Sul, Programa de Pós-Graduação em Ecologia, Porto Alegre, 2009. 146p.

RIMBALDI, D. M.; OLIVEIRA, D. A. S. (Org.). Fragmentação de Ecossistemas: Causas, efeitos sobre a biodiversidade e recomendações de políticas públicas. Brasília: MMA/SBF, 2003. 510p.

SAATY, T. L. A scaling method for priorities in hierarchical structures. Journal of Mathematical Psychology, vol. 15, n. 3, 1977. pp. 234-281.

SAMIZAVA, T. M.; KAIDA, R. H.; IMAI, N. N.; NUNES, J. O. R. SIG aplicado à escolha de áreas potenciais para instalação de aterros sanitários no município de Presidente Prudente-SP. Revista Brasileira de Cartografia, vol. 60, n. 1, 2008. pp. 43-55.

SANTOS, R. F. Planejamento Ambiental: Teoria e Prática. São Paulo: Oficina de Textos, 2004. 184p.

SARTORI, A. A. C.; SILVA, R. F. B.; ZIMBACK, C. R. L. Combinação linear ponderada na definição de áreas prioritárias à conectividade entre fragmentos 
florestais em ambiente SIG. Revista Árvore, vol. 36, n. 6, 2012. pp. 10791090.

SCOSS, L. M. Impacto de estradas sobre mamíferos terrestres: o caso do Parque Estadual do Rio Doce, Minas Gerais. Tese de Doutoramento. Universidade Federal de Viçosa, Programa de Pós-Graduação em Ciência Florestal, Viçosa, 2002. 97p.

SILVA, I. N.; BRENA, A. D.; LONGHI, J. S. Estrutura da regeneração natural em Floresta Ombrófila Mista na Floresta Nacional de São Francisco de Paula, RS. Ciência Florestal, vol. 15, n. 4, 2005. pp. 331-342.

SILVA, J. F.; ECKHARDT, R. R.; REMPEL, C. Análise espaço-temporal das coberturas florestais do município de Roca Sales - RS através de imagens de sensoriamento remoto. Anais XV Simpósio Brasileiro de Sensoriamento Remoto, Curitiba, 2011. pp. 6602-6609.

SILVA, J. S. V. Análise multivariada em zoneamento para planejamento ambiental: estudo de caso: bacia hidrográfica do alto rio Taquari MS/MT. Tese de Doutoramento. Universidade Estadual de Campinas, Programa de Pós-Graduação em Ciências Agrícolas, Campinas, 2003. 307p.

SOSMA, Fundação SOS Mata Atlântica. Atlas dos Remanescentes Florestais da Mata Atlântica (Período 2011-2012). São Paulo: SOSMA, 2013.

SOSMA, Fundação SOS Mata Atlântica. Atlas dos Remanescentes Florestais da Mata Atlântica (Período 2015-2016). São Paulo: SOSMA, 2017. Site $<$ https://www.sosma.org.br/projeto/atlas-da-mata-atlantica/dados-maisrecentes/atlas-dos-municipios/>, acessado em setembro de 2017.

THOMAS, B. L. A categorização e a delimitação de uma Unidade de Conservação como subsídio à sua criação: o caso do Morro Gaúcho, em Arroio do Meio e Capitão/RS. Dissertação de Mestrado. Universidade Federal de Santa Maria, Programa de Pós-Graduação em Geografia, Santa Maria, 2013. 147p.

VALENTE, R. O. A. Definição de áreas prioritárias para conservação e preservação florestal por meio da abordagem multicriterial em ambiente SIG. Tese de Doutoramento. Universidade de São Paulo. Programa de Pós-Graduação em Recursos Florestais, Piracicaba, 2005. 121p. 
VASCONCELLOS, R. P. O Uso do Geoprocessamento na Quantificação de Fragmentos Naturais e Mapeamento de Áreas de Preservação Permanente em Unidades De Conservação - Estudo de Caso da Mata Escura. Trabalho de Conclusão de Especialização. Universidade Federal de Minas Gerais, Curso de Especialização em Geoprocessamento, Belo Horizonte, 2002. 62p.

WIKIAVES. Enciclopédia das Aves do Brasil. Site <http://www.wikiaves.com.br/>, acessado em janeiro de 2016.

XIMENES, A. C.; ALMEIDA, C. M.; AMARAL, S.; ESCADA, M. I. S.; AGUIAR, A. P. D. Modelagem Dinâmica do Desmatamento na Amazônia. Boletim de Ciências Geodésicas, vol. 14, n. 3, 2008. pp. 370-391. 